Sains Malaysiana 48(8)(2019): 1771-1776

http://dx.doi.org/10.17576/jsm-2019-4808-24

\title{
High Breakdown Estimator for Dual Response Optimization in the Presence of Outliers
}

(Penganggar Penguraian Tinggi untuk Pengoptimuman Gerak Balas Dual dengan Kehadiran Titik Terpencil)

\author{
HABSHAH Midi* \& NASUHAR AB. AZIZ
}

\begin{abstract}
Nowadays, dual response surface approach is used extensively, and it is known as one of the powerful tools for robust design. General assumptions are the data is normally distributed, and there is no outlier in the data set. The traditional procedures for robust design is to establish the process location and process scale models of the response variable based on sample mean and sample variance, respectively. Meanwhile, the ordinary least squares (OLS) method is often used to estimate the parameters of the regression response location and scale models. Nevertheless, many statistics practitioners are unaware that these existing procedures are easily influenced by outliers, and hence resulted in less accurate estimated mean response obtained through non-resistant method. As an alternative, the use of MM-location, MM-scale estimator, and MM regression estimator is proposed, in order to overcome the shortcomings of the existing procedures. This study employs a new penalty function optimization scheme to determine the optimum factor settings for robust design variables. The effectiveness of our proposed methods is confirmed by well-known example and Monte Carlo simulations.
\end{abstract}

Keywords: Dual response surface; MM-location and MM-scale; outliers; penalty function optimization

\section{ABSTRAK}

Pada masa kini, pendekatan gerak balas permukaan dual telah digunakan secara meluas, dan ia juga dikenal pasti sebagai salah satu kaedah yang berkuasa untuk reka bentuk teguh. Secara umum, data diandaikan tertabur normal, dan tiada titik terpencil di dalam set data. Prosedur tradisi bagi reka bentuk teguh ialah untuk membina model lokasi dan model skala proses berdasarkan min dan varians sampel. Sementara itu, kaedah kuasa dua terkecil biasa (oLS) sering digunakan untuk menganggar parameter bagi model sambutan regresi untuk proses min dan varians. Walau bagaimanapun, ramai pengamal statistik yang tidak menyedari bahawa prosedur sedia ada sangat senang dipengaruhi oleh titik terpencil dan mengakibatkan penganggaran sambutan min diperoleh daripada kaedah tidak teguh, kurang tepat. Sebagai alternatif, penggunaan kaedah pengganggar teguh MM-lokasi, MM-skala dan MM regresi dicadangkan untuk mengatasi kelemahan prosedur sedia ada. Kajian ini menggunakan skima baru untuk pengoptimunan fungsi penalti bagi menentukan tetapan faktor yang optimum untuk pemboleh ubah reka bentuk teguh. Keberkesanan kaedah baru yang dicadangkan disahkan dengan contoh terkenal dan simulasi Monte Carlo.

Kata kunci: Gerak balas permukaan dual; MM-lokasi dan MM-skala; pengoptimunan fungsi penalti; titik terpencil

\section{INTRODUCTION}

Robust design is an effective method to improve product quality and production methods by determining the optimum factor settings. The objective of this design was to achieve the desired target while keeping the design's variance low at the same time. Robust design has been extensively used among engineers in designing methods to solve engineering problems in order to improve product quality (Dehnad 2012; Velazo et al. 1991). Taguchi was the first person who introduced the concept of robust design in reaching the desired target and maximizing signal-to-noise ratios. However, several authors noted a few drawbacks embodied into Taguchi's approach in robust design (Easterling 1985; Myers et al. 1973; Vining $\&$ Myers 1990). As a result, many research efforts have been made to rectify these weaknesses.
Vining and Myers method (1990), also known as VM method, was the first method which introduced dual response surface optimization (DRSO) using response surface methodology (RSM). This is the method where the response models for process location and scale need to be established at the outset. Furthermore, this method simultaneously optimizes the objective function of process variance, which restricts the process mean towards the desired target. The estimated process location and process scale of the response variables, denoted as $\hat{\mu}(x)$ and $\hat{\sigma}(x)$ were fitted to the second-order polynomial model at each design point where

$$
\hat{\mu}(x)=\hat{\beta}_{o}+\sum_{i=1}^{k} \hat{\beta}_{i} x_{i}+\sum_{i=1}^{k} \sum_{j=1}^{k} \hat{\beta}_{i j} x_{i} x_{j}
$$


and

$$
\hat{\sigma}^{2}(x)=\hat{\gamma}_{o}+\sum_{i=1}^{k} \hat{\gamma}_{i} x_{i}+\sum_{i=1}^{k} \sum_{j=1}^{k} \hat{\gamma}_{i j} x_{i} x_{j}
$$

Hence, the VM method optimization scheme is:

$$
\begin{aligned}
& \operatorname{minimize} \hat{\sigma}^{2}(x) \\
& \text { subject to } \hat{\mu}(x)=\tau
\end{aligned}
$$

where $\tau$ is the target value.

Del Castillo (1993) observed that the VM method using Lagrange multipliers to simultaneously optimize process location and scale. However, this idea might be impractical and definitely imprecise for global best solution, due to restriction of the process location which is assumed equal to specific target value, $\tau$. Thus, Del Castillo (1993) proposed generalized reduced gradient (GRD) technique with inequality constraints to rectify the drawback of the VM optimization method.

Lin and Tu (1995) proposed an optimization scheme based on squared-loss model, which is known as mean square error (MSE). This model deals with square bias and minimizes the variance component of the factor settings. The Lin and Tu (LT) method is to,

$$
\operatorname{minimize} \operatorname{MSE}=(\hat{\mu}(x)-\tau)^{2}+\left(\hat{\sigma}^{2}(x)\right)^{2}
$$

This optimization scheme is widely used in order to find the optimum settings in robust design (Boylan \& Cho 2013; Goethals \& Cho 2011; Park \& Cho 2003; Park \& Leeds 2016). However, the problem with (LT) method is that its function does not clearly specify how far the estimated mean response $\hat{\mu}(x)$ is from the desired target $\tau$. Therefore, Copeland and Nelson (1996) modified LT method by introducing some restrictions or certain limits on the variation of $\hat{\mu}(x)$ with the desired target $\tau$.

Ding et al. (2004) proposed a natural extension of LT method by imposing relative weights on bias and variance term. Their method called weighted MSE (WMSE) is:

$$
\text { minimize WMSE }=w(\hat{\mu}(x)-\tau)^{2}+(1-w) \hat{\sigma}^{2}(x) .
$$

This is the method where $w=$ relative weight factor $(0$ $\leq w \leq 1)$. The data-driven approach is used to determine the value of $w$, but it also has a major weakness. Therefore, Jeong et al. (2005), Lee and Kim (2012) and Ma and Tian (2009) introduced the proper procedure to determine the value of $w$ by taking into the decision maker's preference.

Amongst all of the methods mentioned, most of the existing methods failed to obtain an estimate of mean response close to the target value with small variation. Therefore, Baba et al. (2015) proposed a penalty functionbased approach as another alternative optimization scheme. The Penalty method (PM) is,

$$
\operatorname{minimize}=\left(\frac{\xi}{2}\right)(\hat{\mu}(x)-\tau)^{2}+\hat{\sigma}^{2}(x)
$$

where $\xi$ is the penalty constant $(0 \leq \xi \leq \infty)$. The performance of this method was reported to be more effective compared to the traditional approach.

The response functions for (1) and (2) are generally constructed by the ordinary least squares (OLS) method. Data analyzers prefer OLS due to the universal acceptance, elegant statistical properties and computational simplicity. Moreover, this method has to follow the assumption regarding the experimental data, where the data are assumed to be normally distributed with no outliers or contamination point. This will provide accurate optimal factor settings. The normality assumption can be violated in the presence of one or more outliers in the data set, which results in unreliability of the optimum response. The traditional approach is not resistant to outliers. Therefore, a new approach needs to be established.

In the presence of outliers, Park and Cho (2003) suggested the use of robust location and robust scale as alternative estimators for sample mean and standard deviation. Specifically, the estimators for scale that had been used were inter-quartile range (IQR) and mean absolute deviation (MAD). Besides that, median was used for the robust design's location. The performances of these estimators were reported to be more efficient in terms of smaller bias and mean square error (MSE) when the data were contaminated. Nonetheless, median and MAD were well-known to be inefficient under normality (Bakar \& Midi 2015).

This paper proposes the use of an alternative outlierresistant MM-estimator, introduced by Yohai (1987), to estimate the location and scale of the response variables. This estimator is highly efficient and has a high breakdown point. The MM-estimator is also employed to estimate the parameters of the process location and process scale models.

The next section of this paper gives an overview of various robust location and scale. The proposed optimization procedures are explained in details in the section that follows. Monte Carlo simulation technique was carried out in this research and discussed subsequently. After that, we provide an illustration of a numerical example, and conclusion of this research is as in the last section.

\section{ROBUST LOCATION AND SCALES}

Sample variance and sample mean are expected to be easily affected by outliers. In other words, replacing only one of $n$ observations with large value can negatively affect the value of the sample mean. Tukey (1960) pointed out that this estimator can be heavily influenced by any single outlier, for example, if $Y_{i}$ goes to $\pm \infty$, then $\bar{Y}$ goes to $\pm \infty$. Since the resulting optimum responses are inefficiently determined by the sample variance and mean, Park and Cho (2003) introduced replacement of sample mean with sample median, whereby, MAD and IQR were used as the alternatives to sample variance. These estimators have been successfully applied in various 
areas and are well-known as outlier-resistant estimators. Although these estimators are resistant to outliers, they are not reliable under normality assumption (Lee et al. 2007). To overcome this problem, Park and Leeds (2016) used the Hodges-Lehman estimator and Shamos estimator as alternatives to the location and scale estimate. According to Hettmansperger and McKean (2010), the breakdown point of both Hodges-Lehman estimator and Shamos estimator is $29.3 \%$.

This paper proposes the use of another outlierresistant estimator for estimating the location and scale of the response value. This estimator was proposed by Yohai (1987) and is called the MM-estimator. It is not only highly efficient and robust, but it also has high breakdown property. In addition, the MM-estimator refers to the fact that more than one M-estimation procedures may be used to calculate the final estimate. Consider the following location-scale model:

Let $x_{1}, x_{2}, \ldots, x_{n}$ be $n$ observations on the real line satisfying $x_{i}=\mu+\sigma \varepsilon_{i}$.

where $\varepsilon_{i}, i=1,2, \ldots, n$, is independent, and known as identically distributed (i.i.d) observation with variance equal to 1 . The interest of the model is in estimating $\mu$ and $\sigma$. The procedures for finding MM-estimator are summarized as follows:

Step 1: The S-estimator (Rousseuw 1984) is computed to obtain the initial consistent estimate of the location, $\mu_{0}$ and scale estimate, $\hat{\sigma}_{0}$.

Step 2: Compute residuals $e$ from Step 1 and then compute M estimate of scale, $\hat{\sigma}$ where $\hat{\sigma}$ is the solution to

$$
\frac{1}{n} \sum \rho_{0}\left(\frac{e_{i}}{\hat{\sigma}}\right)=0.5
$$

where $\psi=\rho^{\prime}$ has to be redescending $\rho$ function such as Hampel, Tukey's Bisquare and Tanh . In this paper, we employed Tukey's Bisquare function

Step 3: Compute $\mathrm{M}$ estimate of $\hat{\mu}$ using $\rho_{1}$. Yohai (1987) highlighted that for Tukey's Bisquare weight function, employing $c_{1}=4.68$, result in high efficiency. $\hat{\mu}$ is a solution to $\sum \psi\left(\frac{e_{i}}{\hat{\sigma}}\right) x_{i}=0$ where $\psi=\rho^{\prime}\left(\frac{t}{c_{1}}\right)$, and $t=\frac{e_{i}}{\hat{\sigma}}$. Upon convergence, $\hat{\mu}$ and $\hat{\sigma}$ is the MM location and MM scale estimates. The same procedures were applied to estimate the parameters of models (1-2) with a slight change, where polynomial regression model was considered instead of location model.

In this research, we suggest to employ the MMestimator to estimate the mean and the standard deviation of the response variables and also for estimating the parameters of models (1-2).
This paper suggests an alternative model, called Model $\mathrm{H}$, to compute the location and scale estimates. Model A - G has been proposed by Park and Leeds (2016) in order to estimate the location and scale responses of the $y$. Table 1 shows the various estimators that will be used for comparative analysis.

\section{THE PROPOSED OPTIMIZATION PROCEDURE}

Suppose that $\hat{\mu}(x)$ and $\hat{\sigma}_{\log }^{2}$ are the fitted response functions for the mean and the variance, respectively. According to Park and Leeds (2016), logarithm-transform values for the sample scale response are employed to avoid the possibility of getting negative variance estimates. In practice, the (1) and (2) models are often estimated by using the OLS method (Boylan \& Cho 2013; Park \& Cho 2003; Park $\&$ Leeds 2016). Data analysis based on the least squares estimator is less efficient and not reliable when outliers are present in the data (Riazoshams et al. 2010). As a remedy, robust regression technique has been considered to lessen the effects of outliers. In this research, the MM-regression estimator was used to estimate the parameters for model in (1) and (2) instead of the OLS method.

The main goal of the dual response is to determine the optimum factor setting of the design variable, $x$. In order to get the best overall combination of design point, Park and Leeds (2016) considered the MSE-based optimization scheme as follows:

$$
\operatorname{minimize} \operatorname{MSE}=(\hat{\mu}(x)-\tau)^{2}+\exp \left(\hat{\sigma}_{\log }^{2}(x)\right)^{2} .
$$

As mentioned earlier, this function does not clearly specify how far the estimated mean response $\hat{\mu}(x)$ is from the desired target $\tau$. Therefore, in this study, an alternative optimization scheme, which is based on the penalty function method proposed by Baba et al. (2015) is employed. The Penalty method is to,

$$
\text { Minimize }=\left(\frac{\xi^{*}}{2}\right)(\hat{\mu}(x)-\tau)^{2}+\exp \left(\hat{\sigma}_{\log }^{2}(x)\right)
$$

where $\hat{\mu}(x)$ and $\hat{\sigma}_{\log }^{2}$ are the fitted values based on MMestimator, $\tau$ is the desired value and $\xi$ is penalty constant $(0 \leq \xi \leq \infty)$. Since the possible interval value of $\xi$ is wider, the optimal penalty constant denoted as $\xi^{*}$ is determined by employing the procedure of Jeong et al. (2005). As proven by Lee and Kim (2012), diminishing the less important value of $\xi$ is needed. In this study, the Genetic Algorithm (GA) optimization was used to obtain the optimal factor settings. R software was utilized to analyze this problem.

\section{MONTE CARLO SIMULATION RESULTS AND VERIFICATION}

Monte Carlo simulation is carried out in order to assess the performance of the proposed method (employing the penalty optimization scheme and Model $\mathrm{H}$ ) compared to existing methods (employing the MSE-based optimization scheme and Models (A-G), as shown in Table 1). Following 
TABLE 1. Estimator combination used in comparative analysis

\begin{tabular}{ccc}
\hline Model & Location estimators & Scale estimators \\
\hline Model A & Mean & Variance \\
Model B & Median & MAD \\
Model C & Median & IQR \\
Model D & Hodges-Lehman estimator & Shamos estimator \\
Model E & Median & Shamos estimator \\
Model F & Hodges-Lehman estimator & MAD \\
Model G & Hodges-Lehman estimator & IQR \\
Model H & MM-estimator for location & MM-estimator for scale \\
\hline
\end{tabular}

Park and Cho (2003), five responses $y_{i}=\left(y_{i 1}, y_{i 2}, \ldots, y_{i 5}\right)$ are generated from normal distribution with mean $\mu\left(x_{i}\right)$ and standard deviation $\sigma\left(x_{i}\right)$ at each design point $x_{i}=\left(x_{i 1}\right.$, $\left.x_{i 2}, x_{i 3}\right), i=1,2, \ldots, 27$, which created 135 responses. The iteration is 1000 and assuming the target value was $\tau=50$, the $\mu(x)$ and $\sigma^{2}(x)$ are as shown below:

$$
\begin{aligned}
& \mu\left(x_{i}\right)=50+5\left(x_{1}+x_{2}+x_{3}\right)^{2} \\
& \sigma^{2}\left(x_{i}\right)=100+5\left(x_{i}-0.5\right)^{2}+x_{2}+x_{3} .
\end{aligned}
$$

Next, to see whether the lack of normally distributed responses would affect the estimators, the responses were also generated from Laplace and Logistic distributions.

To further investigate the effect of outliers, the data were contaminated by generating three outliers $(2.2 \%$ contamination) from $N\left(250,10^{2}\right)$. The good data were then replaced by these three outliers, which were the $1^{\text {st }}$ response of the second variable, the $27^{\text {th }}$ observation of the third response variables, and the $14^{\text {th }}$ observation of the fourth response variable.

The new penalty optimization of Baba et al. (2015) based on Model A - Model $\mathrm{H}$ was then applied to the data. In order to see the improvement of the performance on new penalty optimization, the MSE-based optimization scheme in equation (8) was applied. Bias $\left(\hat{\mu}\left(x^{*}\right)-\tau\right)$ and MSE were used as the selection criteria to evaluate the effectiveness of the estimators. Thus, model with smallest values of bias and MSE were sought. The results of the eight models are exhibited in Tables 2 - 5 .

Let us first focus our attention to Tables 2 and 3 for MSE-based optimization scheme. From the performances, it can be seen that the presence of outliers changes the values of bias and MSE dramatically. Model A - Model G are significantly affected by outliers. Furthermore, it can be seen that the values of bias and MSE have significantly increased markedly for normal and non-normal distribution with contamination in the data. Nevertheless, model $\mathrm{H}$ seems to be slightly affected by outliers as indicated by the smaller values of the bias and MSE. Besides that, the bias and MSE also seem to be only slightly changed for distribution considered. Thus, the optimal mean response for model $\mathrm{H}$ is more robust and efficient compared to other well-known conventional models, since it has the smallest bias and MSE for each distribution considered.

The results of Tables 4 and 5 illustrate the performance of the new proposed penalty function optimization scheme. Like the MSE based optimization scheme, it is observed that

TABLE 2. Simulation result based on estimated MSE and bias of the optimal $\hat{\mu}(x *)$ for model A-D with MSE-based optimization scheme

\begin{tabular}{llllllllc}
\hline \multirow{2}{*}{ Distribution } & \multicolumn{2}{c}{ Model A } & \multicolumn{2}{c}{ Model B } & \multicolumn{2}{c}{ Model C } & \multicolumn{2}{c}{ Model D } \\
\cline { 2 - 9 } & Bias & MSE & Bias & MSE & Bias & MSE & Bias & MSE \\
\hline Normal & 1.23 & 3.05 & 0.92 & 2.00 & 0.82 & 1.68 & 1.57 & 4.90 \\
Normal Contaminated & 0.74 & 3.32 & 1.14 & 3.03 & 1.01 & 2.26 & 1.83 & 6.89 \\
Laplace & 1.62 & 6.16 & 1.07 & 2.85 & 0.88 & 1.99 & 1.79 & 7.40 \\
Logistic & 2.34 & 11.66 & 1.68 & 6.39 & 1.50 & 5.03 & 2.69 & 15.14 \\
\hline
\end{tabular}

TABLE 3. Simulation result based on estimated MSE and bias of the optimal $\hat{\mu}\left(x^{*}\right)$

\begin{tabular}{|c|c|c|c|c|c|c|c|c|}
\hline \multirow{2}{*}{ Distribution } & \multicolumn{2}{|c|}{ Model E } & \multicolumn{2}{|c|}{ Model F } & \multicolumn{2}{|c|}{ Model G } & \multicolumn{2}{|c|}{ Model H } \\
\hline & Bias & MSE & Bias & MSE & Bias & MSE & Bias & MSE \\
\hline Normal & 1.48 & 4.52 & 0.94 & 2.06 & 0.86 & 1.84 & 0.74 & 1.05 \\
\hline Normal Contaminated & 1.77 & 6.38 & 1.26 & 3.46 & 1.06 & 2.40 & 0.86 & 2.36 \\
\hline Laplace & 1.76 & 7.16 & 1.11 & 3.41 & 0.90 & 2.21 & 0.80 & 1.95 \\
\hline Logistic & 2.59 & 14.59 & 1.69 & 6.83 & 1.57 & 5.64 & 1.21 & 3.79 \\
\hline
\end{tabular}
for model E-H with MSE-based optimization scheme 
TABLE 4. Simulation result based on estimated MSE and bias of the optimal $\hat{\mu}(x *)$ for model A-D with new penalty function-based optimization scheme

\begin{tabular}{lllllllll}
\hline \multirow{2}{*}{ Distribution } & \multicolumn{2}{c}{ Model A } & \multicolumn{2}{c}{ Model B } & \multicolumn{2}{c}{ Model C } & \multicolumn{2}{c}{ Model D } \\
\cline { 2 - 9 } & Bias & MSE & Bias & MSE & Bias & MSE & Bias & MSE \\
\hline Normal & 0.25 & 0.10 & 0.20 & 0.18 & 0.14 & 0.07 & 0.23 & 0.23 \\
Normal Contaminated & 0.23 & 0.33 & 0.15 & 0.09 & 0.10 & 0.04 & 0.11 & 0.05 \\
Laplace & 0.11 & 0.11 & 0.16 & 0.08 & 0.16 & 0.14 & 0.07 & 0.12 \\
Logistic & 0.43 & 0.48 & 0.26 & 0.24 & 0.19 & 0.13 & 0.79 & 1.62 \\
\hline
\end{tabular}

TABLE 5. Simulation result based on estimated MSE and bias of the optimal $\hat{\mu}\left(x^{*}\right)$ for model E-H with new penalty function-based optimization scheme

\begin{tabular}{|c|c|c|c|c|c|c|c|c|}
\hline \multirow{2}{*}{ Distribution } & \multicolumn{2}{|c|}{ Model E } & \multicolumn{2}{|c|}{ Model F } & \multicolumn{2}{|c|}{ Model G } & \multicolumn{2}{|c|}{ Model H } \\
\hline & Bias & MSE & Bias & MSE & Bias & MSE & Bias & MSE \\
\hline Normal & 0.24 & 0.26 & 0.13 & 0.05 & 0.14 & 0.06 & 0.05 & 0.03 \\
\hline Normal Contaminated & 0.07 & 0.05 & 0.11 & 0.06 & 0.06 & 0.02 & 0.05 & 0.03 \\
\hline Laplace & 0.11 & 0.22 & 0.21 & 0.12 & 0.05 & 0.03 & 0.07 & 0.05 \\
\hline Logistic & 0.86 & 1.67 & 0.46 & 0.58 & 0.22 & 0.19 & 0.10 & 0.08 \\
\hline
\end{tabular}

model H's performance is more superior relative to other models under different probability distribution functions. Model $\mathrm{H}$ consistently having the smallest bias and MSE compared to the other seven models, regardless of the optimization scheme.

Next, a comparison was made between the performance of the proposed penalty optimization scheme and the MSE-based optimization scheme. The results of Tables 2 and 5 clearly show that the propose penalty optimization scheme possesses smaller bias and MSE for all models (A-H) compared to the MSE-based optimization scheme irrespective of the distribution functions considered in this study. This shows that the proposed scheme outperformed the existing scheme.

\section{NUMERICAL EXAMPLES}

This example was taken from the case study performed by Park and Cho (2003). The experiment consisted of $3^{3}$ factorial design with three control factors, namely mold temperature $\left(x_{1}\right)$, humidity $\left(x_{2}\right)$ and, the injection flow rate $\left(x_{3}\right)$. The objective of the study was to investigate the effects of the three control factors on the coating thickness $\left(y_{i j}\right)$ of wafers. The desired target value was $\tau=50$ microns and five replicates were made at each of the 27 design points. Three contaminated data were observed at $y_{10,2}=239$, $y_{17,4}=238$ and $y_{25,3}=244$. Since the unusual observations occurred in the data series, the outlier-resistant estimators are believed to be more suitable to be used in order to find the optimal operating conditions. Therefore, the sample mean $(\bar{y})$, log-transformation variance $\left(\sigma_{\log }^{2}\right)$, median $(\tilde{Y})$, $\log$-transformation MAD square $\left(D_{\log }^{2}\right), \log$-transformation IQR square $\left(\mathrm{IQR}_{\log }^{2}\right)$, Hodges-Lehman location estimator (HL), log-transformation Shamos estimator square $\left(\mathrm{Sn}_{\log }^{2}\right)$, MM-location estimator (ML) and log-transformation MMscale estimator $\left(\mathrm{MS}_{\mathrm{log}}^{2}\right)$ at each design points are computed.

All the eight preceding models were used to estimate the mean and the variance of the response $y$. Table 6 reports the optimal settings, bias and MSE of the estimated mean responses based on the eight models involved in this study. It can be seen from the study that Model $\mathrm{H}$ has the least bias, variance and MSE compared to the other models. The results of this case study were consistent with the simulation results in Monte Carlo Simulation Results and Verification section.

TABLE 6. Estimates generated using alternative estimators with new penalty optimization scheme

\begin{tabular}{ccccc}
\hline Model & Optimal settings & Bias & Variance & MSE \\
\hline A & $(0.017,-0.067,-1.00)$ & 2.52 & 3.89 & 10.24 \\
B & $(0.011,0.124,-0.963)$ & 4.80 & 3.43 & 26.47 \\
C & $(-0.229,0.345,-0.732)$ & 3.78 & 3.25 & 17.54 \\
D & $(-0.08,0.055,-0.901)$ & 4.27 & 3.95 & 22.18 \\
E & $(-0.012,0.043,-0.817)$ & 3.64 & 4.03 & 17.28 \\
F & $(-0.102,0.153,-1.00)$ & 4.97 & 3.30 & 28.00 \\
G & $(-0.196,0.265,-0.834)$ & 4.24 & 3.12 & 21.10 \\
H & $(-0.18,0.444,-0.899)$ & 1.32 & 3.42 & 5.16 \\
\hline
\end{tabular}




\section{CONCLUSION}

The main focus of this study was to propose using the MM estimator to estimate the location and scale estimators of the response variables as well as to estimate the parameters of the process location and scale models. We also propose employing a new penalty function optimization scheme to obtain the optimal factor settings and subsequently estimating the optimal mean response. On the other hand, the existing procedures compute process location and process scale based on different location and scale estimators as exhibited in Table 1. Moreover, the Ordinary Least Square (OLS) is used to estimate the parameters of the process location and scale models and employed the MSEbased optimization scheme. The Monte Carlo simulations studies and numerical example were carried out to compare the performance of the newly proposed method with the existing methods. The simulations and numerical example have shown that, the newly proposed method offers substantial improvement over the existing methods. The proposed method can significantly reduce bias, variance and MSE of the estimated mean response regardless of the distribution functions considered in this study.

\section{ACKNOWLEDGMENTS}

The authors would like to thanks the Ministry of Higher Education, Vot no. FRGS 5524814 for the financial support.

\section{REFERENCES}

Baba, I., Midi, H., Rana, S. \& Ibragimov, G. 2015. An alternative approach of dual response surface optimization based on penalty function method. Mathematical Problems in Engineering 2015: 450131.

Bakar, N.M. \& Midi,H. 2015. Robust centering in the fixed effect panel data model. Pakistan Journal of Statistics 31(1): 33-48.

Boylan, G.L. \& Cho, B.R. 2013. Comparative studies on the high-variability embedded robust parameter design from the perspective of estimators. Computers \& Industrial Engineering 64(1): 442-452.

Copeland, K.A. \& Nelson, P.R. 1996. Dual response optimization via direct function minimization. Journal of Quality Technology 28(3): 331-336.

Dehnad, K. 2012. Quality Control, Robust Design, and the Taguchi Method. Springer Science \& Business Media.

Del Castillo, E. \& Montgomery, D.C. 1993. A nonlinear programming solution to the dual response problem. Journal of Quality Technology 25(3): 199-204.

Ding, R., Lin, D.K. \& Wei, D. 2004. Dual-response surface optimization: A weighted MSE approach. Quality Engineering 16(3): 377-385.

Easterling, R. 1985. Discussion of off-line quality control, parameter design, and the Taguchi Method. Journal of Quality Technology 17: 191-193.

Goethals, P.L. \& Cho, B.R. 2011. Solving the optimal process target problem using response surface designs in heteroscedastic conditions. International Journal of Production Research 49(12): 3455-3478.
Hettmansperger, T.P. \& McKean, J.W. 2010. Robust Nonparametric Statistical Methods. Boca Raton: CRC Press.

Jeong, I.J., Kwang-Jae, K. \& Chang, S.Y. 2005. Optimal weighting of bias and variance in dual response surface optimization. Journal of Quality Technology 37(3): 236-247.

Lee, D.H. \& Kim, K.J. 2012. Interactive weighting of bias and variance in dual response surface optimization. Expert Systems with Applications 39(5): 5900-5906.

Lee, S.B., Park, C. \& Cho, B.R. 2007. Development of a highly efficient and resistant robust design. International Journal of Production Research 45(1): 157-167.

Lin, D.K. \& Tu, W. 1995. Dual response surface optimization. Journal of Quality Technology 27(1): 34-39.

Ma, Y. \& Tian, T. 2009. Optimal weighted approach in dualresponse surface optimization. 2009 International Conference on Management and Service Science DOI: 10.1109/ icmss.2009.5305063.

Myers, R.H. \& Carter, W.H. 1973. Response surface techniques for dual response systems. Technometrics 15(2): 301-317.

Park, C. \& Cho, B.R. 2003. Development of robust design under contaminated and non-normal data. Quality Engineering 15(3): 463-469.

Park, C. \& Leeds, M. 2016. A highly efficient robust design under data contamination. Computers \& Industrial Engineering 93: 131-142.

Riazoshams, H., Midi, H.B. \& Sharipov, O.S. 2010. The performance of robust two-stage estimator in nonlinear regression with autocorrelated error. Communications in Statistics-Simulation and Computation 39(6): 1251-1268.

Tukey, J.W. 1960. A survey of sampling from contaminated distributions. Contributions to Probability and Statistics 2: 448-485.

Velazco, E.E., Bendell, A., Disney, J. \& Pridmore, W.A. 1991. Taguchi Methods: Applications in world industry. Interfaces 21(2): 99-101.

Vining, G. \& Myers, R. 1990. Combining Taguchi and response surface philosophies-A dual response approach. Journal of Quality Technology 22(1): 38-45.

Yohai, V.J. 1987. High breakdown-point and high efficiency robust estimates for regression. The Annals of Statistics 15(2): 642-656.

Habshah Midi* \& Nasuhar Ab.Aziz

Department of Mathematics

Faculty of Science

Universiti Putra Malaysia

43400 Serdang, Selangor Darul Ehsan

Malaysia

Nasuhar Ab. Aziz

Faculty of Computer \& Mathematical Sciences

Universiti Teknologi MARA, Cawangan Kelantan

18500 Machang, Kelantan Darul Naim

Malaysia

*Corresponding author; email: habshahmidi@gmail.com

Received: 18 April 2017

Accepted: 30 May 2019 